\title{
BMJ Open Association between Hashimoto's thyroiditis and cholelithiasis: a retrospective cohort study in Taiwan
}

\author{
Chien-Hua Chen, ${ }^{1,2,3,4}$ Cheng-Li Lin, ${ }^{5,6}$ Chia-Hung Kao ${ }^{7,8,9}$
}

To cite: Chen C-H, Lin C-L, Kao C-H. Association between Hashimoto's thyroiditis and cholelithiasis: a retrospective cohort study in Taiwan. BMJ Open 2018;8:e020798. doi:10.1136/ bmjopen-2017-020798

- Prepublication history for this paper is available online. To view these files,please visit the journal online (http://dx.doi org/10.1136/bmjopen-2017020798).

Received 29 November 2017 Revised 22 June 2018 Accepted 8 August 2018

Check for updates

(C) Author(s) (or their employer(s)) 2018. Re-use permitted under CC BY-NC. No commercial re-use. See rights and permissions. Published by BMJ.

For numbered affiliations see end of article.

Correspondence to

Dr Chia-Hung Kao;

d10040@mail.cmuh.org.tw

\section{ABSTRACT}

Objective To investigate the relation of Hashimoto's thyroiditis (HT) to cholelithiasis and cholecystectomy in a retrospective population-based study.

Setting Cohort study.

Participants We identified 1268 patients aged $\geq 20$ years with HT between 2000 and 2010 as the study cohort. Primary and secondary outcome measures Patients without HT were randomly selected from a database and propensity-matched with the study cohort at a 1:4 ratio according to age, sex, comorbidities and year of the index date to measure the incidence of cholelithiasis and cholecystectomy.

Results The cumulative incidence of cholelithiasis was higher in the HT cohort than that in the non-HT cohort (log-rank test, $p<0.001)$, with a 1.91-fold higher risk of choleithiasis ( $95 \% \mathrm{Cl} 1.58$ to 2.33 ) after adjustment for comorbidities. The age-specific relative risk of cholelithiasis in the HT cohort was higher than that in the non-HT cohort for patients aged $\geq 50$ years (adjusted $\mathrm{HR}(\mathrm{aHR})=2.59,95 \% \mathrm{Cl} 1.33$ to 5.03$)$. The sex-specific relative risk of cholelithiasis in the HT cohort was higher than that in the non-HT cohort for women (aHR=1.99, $95 \% \mathrm{Cl} 1.63$ to 2.44). Compared with those in the non$\mathrm{HT}$ cohort, patients with $\mathrm{HT}$ without $(\mathrm{aHR}=1.95,95 \% \mathrm{Cl}$ 1.53 to 2.49 ) and with (aHR=1.94, 95\% $\mathrm{Cl} 1.51$ to 2.49 ) thyroxine treatment were associated with a higher risk of cholelithiasis. Compared with those in the non-HT cohort, patients with $\mathrm{HT}$ had a higher risk of cholecystectomy (aHR=1.28, 95\% Cl 1.02 to 1.61).

Conclusions Inability to obtain information on several potential confounding factors and misclassification of important covariates are the major limitations of the study. Our study indicates HT per se was associated with the development of cholelithiasis, which has been validated by the association between cholecystectomy and HT. Surveys and health education on cholelithiasis in women aged $\geq 50$ years with HT should be considered by clinicians, and further prospective research should be done on this topic.

\section{INTRODUCTION}

Cholelithiasis involves gallbladder stones, intrahepatic stones (IHS) and common bile duct (CBD) stones. Among the subtypes of cholelithiasis, the reported proportion of gallbladder stones was approximately $85 \%$, that of CBD stones was $19 \%$ and that of IHS was $11 \%-15 \% .^{1-3}$ The prevalence of cholelithiasis

\section{Strengths and limitations of this study}

The strengths of our study are its population-based design, use of a single administrative database analysis with the National Health Insurance Research Database records, and generalisability of findings with a very large sample size including study and control cohorts.

- The association between Hashimoto's thyroiditis (HT) and cholelithiasis, either symptomatic or asymptomatic, as well as between HT and cholecystectomy, was assessed to validate the aforementioned association and to diminish the possibility of surveillance bias.

- The retrospective cohort study is subject to many biases related to the necessary adjustments for confounding factors.

- The evidence derived from a retrospective cohort study is generally of lower methodological quality than that from randomised trials, and the causal relationship of HT to cholelithiasis and cholecystectomy could not be ascertained in this study.

varies with ethnicity, environment, lifestyle and dietary habits. The reported prevalence of cholelithiasis in the USA ranged between $10 \%$ and $12 \%$, whereas that in Taiwan ranged between $5 \%$ and $10 \% .^{4-6}$ Of individuals with gallbladder stones, $20 \%$ were reported to experience biliary symptoms in their lifetime, and approximately 1\%-2\% of patients with gallbladder stones require surgery annually. ${ }^{7}$ Nearly $10 \%-15 \%$ of patients with CBD stones were reported to harbour concomitant gallbladder stones, which were considered to be the origin of stone migration, and the remaining patients $(85 \%-90 \%)$ were considered to present de novo stones in the CBD. ${ }^{8}$ Approximately $10 \%$ of patients with CBD stones remained asymptomatic; however, only $2 \%$ of patients with CBD stones exhibited no signs of elevated liver function tests, dilated CBD, jaundice or pancreatitis. ${ }^{9}$ Therefore, the extraction of CBD stones is recommended if possible, regardless of whether they are symptomatic. ${ }^{10}$ More than $50 \%$ of 
patients with IHS experience suppurative cholangitis or cholangiocarcinoma if the stones are not completely retrieved. ${ }^{11}$ In brief, cholelithiasis is one of the common morbidities among the adult population, and it is a major public health concern because of its potential development to cholecystitis, cholangitis, pancreatitis and biliary tract cancers.

Hashimoto's thyroiditis (HT) often leads to hypothyroidism, resulting from chronic destruction of the thyroid gland by an autoimmune process. ${ }^{12}$ The reported prevalence of HT in Western countries was approximately $0.1 \%-5 \%$, and women exhibited a 10-fold to 20-fold higher risk of harbouring HT. ${ }^{13}$ The diagnosis of HT is mainly based on the presence of circulating antibodies to thyroperoxidase or thyroglobulin, reduced echogenicity on thyroid ultrasound, and manifestations of compression of organs adjacent to the thyroid gland. The utilisation of radioactive iodine or cytological examinations of thyroid aspirate was rarely applied in clinical practice. ${ }^{14}$ Moreover, HT was more prevalent in middle-aged individuals (between 45 and 65 years). HT is reported to be both the most common endocrine disorder and the most common cause of hypothyroidism. ${ }^{14}$

Hypothyroidism is a well-known risk factor for cholelithiasis, particularly for gallstone diseases (GSD). However, not all patients will develop hypothyroidism, and they sometimes present euthyroid or hyperthyroid features. ${ }^{15}$ It has been reported that either euthyroidism or subclinical hypothyroidism in children with HT frequently evolved towards clinical hypothyroidism, whereas those presenting with overt hyperthyroidism always had definitive resolution of hyperthyroid to evolve towards euthyroidism or hypothyroidism. ${ }^{16}{ }^{17}$ Furthermore, the association between HT and cholelithiasis has never been discussed in the literature. In this study, we hypothesised that HT per se is associated with an increased risk of cholelithiasis. We conducted a nationwide population-based cohort study by analysing data from the Longitudinal Health Insurance Research Database (LHID2000) of the Taiwan National Health Insurance Research Database (NHIRD) to determine the association between HT and the subsequent development of cholelithiasis, either symptomatic or asymptomatic, in considering the confounding factors of hypothyroidism and hyperthyroidism. Furthermore, we also assessed the association between HT and cholecystectomy to diminish surveillance bias and to validate the aforementioned association between HT and cholelithiasis.

\section{METHODS}

\section{Data source}

This was a nationwide cohort study using the LHID2000 of the NHIRD, which contains claims data of the beneficiaries of the National Health Insurance (NHI) programme in Taiwan. ${ }^{18}$ In brief, this NHI programme began on 1 March 1995, and covers approximately $99 \%$ of the 23.74 million residents of Taiwan. The details of the NHI programme and LHID2000 have been thoroughly addressed in previous studies. ${ }^{19}{ }^{20}$ Diseases were coded according to the 2001 International Classification of Diseases, Ninth Revision, Clinical Modification (ICD-9-CM).

\section{Patient and public involvement statement}

Figure 1 shows the selection process of the participants in the two study cohorts. This study recruited patients with newly diagnosed HT (ICD-9 code 245.2) who were aged $\geq 20$ years from LHID2000 between 1 January 2000 and 31 December 2010. The date of diagnosis of HT was defined as the index date. The control cohort was randomly selected from LHID2000 and included patients without a history of HT who were propensity-matched with the case cohort at a ratio of $4: 1$. Non-HT control patients were frequency-matched with respect to age group (every 5-year span); sex; comorbidities of hyperlipidaemia, diabetes, liver cirrhosis, alcohol-related illness, hypertension, chronic obstructive pulmonary disease (COPD), obesity, stroke, coronary artery disease (CAD), hepatitis $B$ virus, hepatitis $\mathrm{C}$ virus and inflammatory bowel disease (IBD); and index year of HT diagnosis. The index date for control patients was randomly appointed based on the month and day with the same index year of the matched patients. We also considered hyperthyroidism and hypothyroidism as comorbidities. Patients with a history of cholelithiasis (ICD-9-CM code 574) and those with incomplete information on age or sex at baseline were excluded from both the HT and non-HT cohorts. Each patient was examined from the index date until the occurrence of cholelithiasis, death, withdrawal from the NHI programme or the end of 31 December 2011. Individuals who emigrated out of Taiwan or who died are withdrawn from the NIH programme. Both identified cause-specific and non-cause-specific deaths were included in the analysis, whereas deaths were censored if the cause could not be identified.

\section{Statistical analysis}

The distributions of age, sex and comorbidities between the HT and non-HT cohorts were compared and examined using the $\chi^{2}$ test. The mean ages (SDs) and mean follow-up period (SDs) between the cohorts were compared and tested using Student's t-test. The KaplanMeier method was used to compare the cumulative incidence of cholelithiasis events and survival between the cohorts, and the log-rank test was used to examine the differences. Cholelithiasis incidence density rates were estimated by dividing the number of cholelithiasis events by the number of person-years for each risk factor, and the results were then stratified by age, sex, and presence or absence of a comorbidity. Univariable and multivariable Cox proportional hazard regression models were used to assess the risk of cholelithiasis associated with HT. The HRs and 95\% CIs were estimated using the Cox model, which were adjusted for age, sex, and comorbidities of hyperlipidaemia, diabetes, liver cirrhosis, hypertension, 


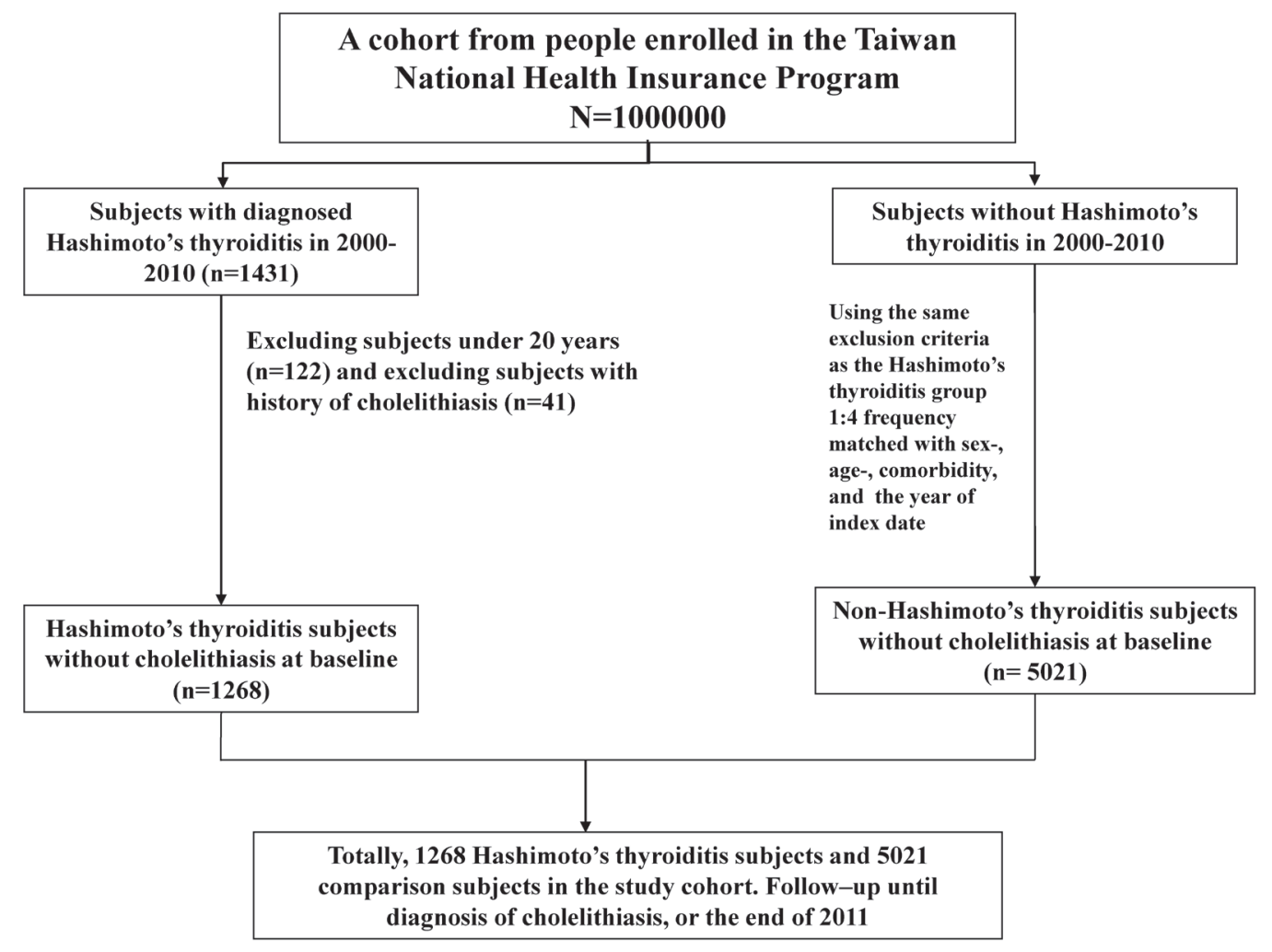

Figure 1 Selection process of the participants in the two study cohorts.

COPD, CAD, IBD, hyperthyroidism and hypothyroidism. Multivariable Cox proportional hazard regression models were also used to assess the association between cholecystectomy and HT. All data analyses were performed using SAS V.9.4. The significance level was set at two-tailed $\mathrm{p}<0.05$.

\section{RESULTS}

The study examined an HT cohort of 1268 patients and a non-HT cohort of 5021 patients (table 1). The HT and non-HT cohorts were well matched for age, sex and comorbidities. The mean ages in the HT and non-HT cohorts were $42.7 \pm 13.6$ and $42.4 \pm 13.8$ years, respectively. Most patients were older than 35 years $(65.5 \%)$ and were women $(90.0 \%)$. Excluding hyperthyroidism and hypothyroidism, the top three common comorbidities according to the order of frequency in these study cohorts were hypertension $(18.0 \%)$, hyperlipidaemia (17.8\%) and CAD $(10.8 \%)$. It was noted that hyperthyroidism and hypothyroidism were more prevalent in the HT cohort than in the non-HT cohort. Of the 367 patients of the HT cohort with a history of hyperthyroidism, 171 (46.6\%) patients had history of Graves' disease (GD) before evolving to HT. Of the 96 patients of non-HT cohort with a history of hyperthyroidism, $41(42.7 \%)$ patients had history of GD.

Figure 2 shows the cumulative incidences $(100 \%)$ of cholelithiasis in the HT and the non-HT cohorts during the follow-up period. The cumulative incidence of cholelithiasis was higher in the HT cohort than that in the non-HT cohort (log-rank test, $\mathrm{p}<0.001)$. The average follow-up duration was 5.91 \pm 3.24 years for the HT cohort and $5.88 \pm 3.22$ years for the non-HT cohort.

Table 2 presents the incidence of and risk factors for cholelithiasis. The overall incidence density rates of cholelithiasis in the HT and non-HT cohorts were 3.74 and 2.24 per 1000 person-years, respectively. Compared with patients without HT, those with HT were associated with an increased risk of cholelithiasis (adjusted HR $(\mathrm{aHR})=1.91,95 \%$ CI 1.58 to 2.33) after adjustment for age, sex, and comorbidities of hyperlipidaemia, diabetes, liver cirrhosis, hypertension, COPD, CAD, IBD, hyperthyroidism and hypothyroidism. HT was found to be consistently associated with the development of cholelithiasis (aHR=1.96, 95\% CI 1.60 to 2.40$)$ after we excluded the 171 patients with a history of GD before evolving to HT to avoid enrolling a more varied autoimmune thyroid disease group into the HT cohort (data not shown). Compared with patients aged $\leq 34$ years, the risk of cholelithiasis was 2.14-fold higher in those aged $35-49$ years (95\% CI 1.67 to 2.75 ) and 4.33-fold higher in those aged $\geq 50$ years ( $95 \%$ CI 3.33 to 5.64 ). Multivariable analysis for comorbidities revealed that hyperlipidaemia $(\mathrm{aHR}=1.39,95 \% \mathrm{CI} 1.15$ to 1.68$)$, diabetes $(\mathrm{aHR}=1.55$, $95 \%$ CI 1.22 to 1.97$)$, liver cirrhosis $(\mathrm{aHR}=2.27,95 \%$ CI 1.07 to 4.85 ), $\mathrm{CAD}$ (aHR=2.04, 95\% CI 1.67 to 2.50 ) and IBD $(\mathrm{aHR}=3.21,95 \%$ CI 1.87 to 5.52$)$ remained the independent risk factors for cholelithiasis. 


Table 1 Demographic characteristics and comorbidities of
cohorts with and without Hashimoto's thyroiditis

\begin{tabular}{|c|c|c|c|}
\hline \multirow[b]{3}{*}{ Variable } & \multicolumn{2}{|c|}{ Hashimoto's thyroiditis } & \multirow[b]{3}{*}{$P$ values } \\
\hline & No & Yes & \\
\hline & $n=5021$ & $n=1268$ & \\
\hline Age, year & & & 0.98 \\
\hline$\leq 34$ & $1743(34.7)$ & $437(34.5)$ & \\
\hline $35-49$ & $1886(37.6)$ & $476(37.5)$ & \\
\hline $50+$ & $1392(27.7)$ & $355(28.0)$ & \\
\hline Mean $\pm \mathrm{SD}^{*}$ & $42.4(13.8)$ & $42.7(13.6)$ & 0.57 \\
\hline Sex & & & 0.97 \\
\hline Female & $4520(90.0)$ & $1141(90.0)$ & \\
\hline Male & $501(9.98)$ & $127(10.0)$ & \\
\hline \multicolumn{4}{|l|}{ Comorbidity } \\
\hline Hyperlipidaemia & $881(17.6)$ & $226(17.8)$ & 0.82 \\
\hline Diabetes & $302(6.01)$ & $80(6.31)$ & 0.69 \\
\hline Liver cirrhosis & $22(0.44)$ & $9(0.71)$ & 0.22 \\
\hline $\begin{array}{l}\text { Alcohol-related } \\
\text { illness }\end{array}$ & 98 (1.95) & $30(2.37)$ & 0.35 \\
\hline Hypertension & $886(17.7)$ & $228(18.0)$ & 0.78 \\
\hline $\begin{array}{l}\text { Chronic } \\
\text { obstructive } \\
\text { pulmonary } \\
\text { disease }\end{array}$ & $379(7.55)$ & $102(8.04)$ & 0.55 \\
\hline Obesity & $166(3.31)$ & $44(3.47)$ & 0.77 \\
\hline Stroke & $44(0.88)$ & $14(1.10)$ & 0.45 \\
\hline $\begin{array}{l}\text { Coronary artery } \\
\text { disease }\end{array}$ & $524(10.4)$ & $137(10.8)$ & 0.70 \\
\hline Hepatitis B virus & $183(3.64)$ & 49 (3.86) & 0.71 \\
\hline Hepatitis $C$ virus & $69(1.37)$ & $20(1.58)$ & 0.58 \\
\hline $\begin{array}{l}\text { Inflammatory } \\
\text { bowel disease }\end{array}$ & $26(0.52)$ & $9(0.71)$ & 0.41 \\
\hline Hyperthyroidism & 96 (1.91) & 367 (28.9) & $<0.001$ \\
\hline Hypothyroidism & $26(0.52)$ & 277 (21.9) & $<0.001$ \\
\hline
\end{tabular}

Table 3 presents the comparison of the cholelithiasis incidence densities between patients with and without HT stratified by demographic characteristics and the presence or absence of a comorbidity. The age-specific relative risk of cholelithiasis in the HT cohort was higher than that in the non-HT cohort for patients aged $\geq 50$ years $(\mathrm{aHR}=2.59,95 \% \mathrm{CI} 1.33$ to 5.03$)$. The sex-specific relative risk of cholelithiasis in the HT cohort was higher than that in the non-HT cohort for women $(\mathrm{aHR}=1.99$, $95 \%$ CI 1.63 to 2.44 ). The comorbidity-specific relative risk of cholelithiasis in the HT cohort was higher than that in the non-HT cohort for patients without comorbidities $(\mathrm{aHR}=2.29,95 \%$ CI 1.77 to 2.95$)$ or with comorbidities (aHR $=1.38,95 \%$ CI 1.08 to 1.76$)$.

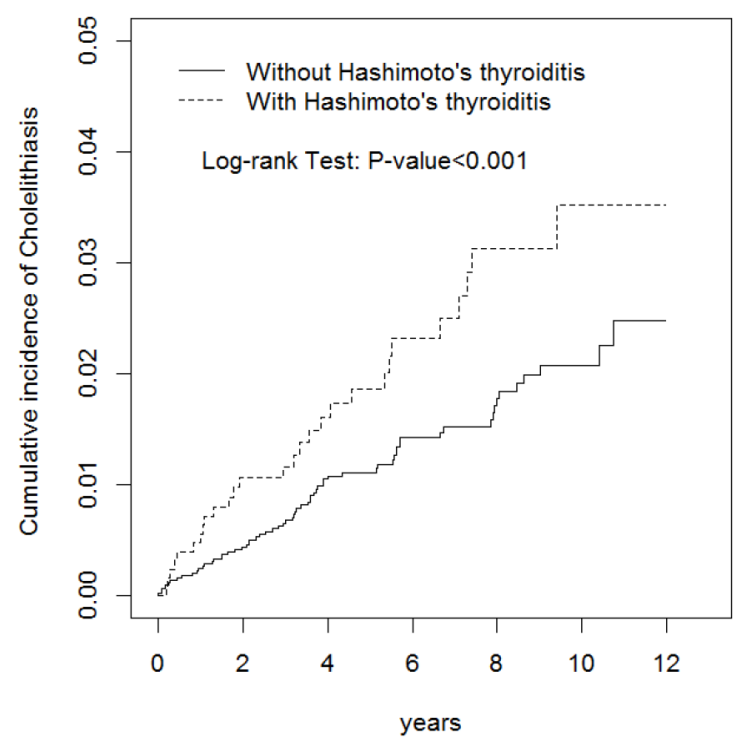

Figure 2 Cumulative incidences (100\%) of cholelithiasis in the HT and the non-HT cohorts. HT, Hashimoto's thyroiditis.

Compared with those in the non-HT cohort, patients with HT without (aHR=1.95, 95\% CI 1.53 to 2.49 ) and with $(\mathrm{aHR}=1.94,95 \%$ CI 1.51 to 2.49$)$ thyroxine treatment were associated with a higher risk of cholelithiasis (table 4).

Table 5 shows the overall incidence of cholecystectomy and estimated HRs according to HT status by Cox proportional hazard regression model. Compared with those in the non-HT cohort, patients with HT had a higher risk of cholecystectomy (aHR=1.28, 95\% CI 1.02 to 1.61). Similarly, HT was consistently associated with the risk of cholecystectomy (aHR $=1.33$, 95\% CI 1.05 to 1.69 ) after we excluded the 171 patients with a history of GD from the HT cohort (data not shown).

\section{DISCUSSION}

We observed that the prevalence of HT was higher in women $(90.0 \%)$ and in patients older than 35 years $(65.5 \%)$, with a mean age of $42.7 \pm 13.6$ years. Furthermore, the age-specific relative risk of cholelithiasis in the HT cohort was higher than that in the non-HT cohort for patients aged $\geq 50$ years, and the sex-specific relative risk of cholelithiasis in the HT cohort was higher than that in the non-HT cohort for women (table 3). These findings reflect the concerns regarding the survey of cholelithiasis in women aged $\geq 50$ years with HT. Furthermore, the reasons for no relationship between male gender and age $<50$ years with increased cholelithiasis incidence in patients with HT might be due to the smaller study populations of men $(n=127)$ and the smaller case number of cholelithiasis (44 of 913), respectively.

Excluding hyperthyroidism and hypothyroidism, our findings were consistent with the literature to demonstrate that the top three common comorbidities associated with HT were hypertension, hyperlipidaemia and 
Table 2 Incidence and risk factors for cholelithiasis

\begin{tabular}{|c|c|c|c|c|c|}
\hline Variable & Event & $\begin{array}{l}\text { Person- } \\
\text { years }\end{array}$ & Rate† & Crude HR (95\% CI) & Adjusted HR $¥(95 \% \mathrm{Cl})$ \\
\hline \multicolumn{6}{|c|}{ Hashimoto's thyroiditis } \\
\hline Yes & 28 & 7489 & 3.74 & $1.67(1.41 \text { to } 1.99)^{\star * *}$ & $1.91(1.58 \text { to } 2.33)^{\star \star \star}$ \\
\hline \multicolumn{6}{|l|}{ Age, year } \\
\hline $50+$ & 50 & 9190 & 5.44 & $5.71(4.51 \text { to } 7.23)^{\star \star *}$ & $4.33(3.33 \text { to } 5.64)^{\star \star *}$ \\
\hline \multicolumn{6}{|l|}{ Sex } \\
\hline Female & 83 & 33763 & 2.46 & 1.00 & 1.00 \\
\hline Male & 11 & 3234 & 3.40 & $1.38(1.08 \text { to } 1.72)^{*}$ & 1.07 (0.84 to 1.37$)$ \\
\hline Yes & 32 & 6205 & 5.16 & $2.56(2.17 \text { to } 3.03)^{\star \star \star}$ & $1.39(1.15 \text { to } 1.68)^{\star \star \star}$ \\
\hline \multicolumn{6}{|c|}{ Diabetes } \\
\hline No & 81 & 34947 & 2.32 & 1.00 & 1.00 \\
\hline Yes & 13 & 2050 & 6.34 & $2.74(2.17 \text { to } 3.44)^{\star \star \star}$ & $1.55(1.22 \text { to } 1.97)^{\star \star \star}$ \\
\hline \multicolumn{6}{|c|}{ Liver cirrhosis } \\
\hline No & 93 & 36889 & 2.52 & 1.00 & 1.00 \\
\hline Yes & 1 & 110 & 9.07 & $3.60(1.66 \text { to } 7.82)^{\star \star}$ & $2.27(1.07 \text { to } 4.85)^{\star \star \star}$ \\
\hline \multicolumn{6}{|c|}{ Alcohol-related illness } \\
\hline No & 85 & 34669 & 2.45 & 1.00 & 1.00 \\
\hline Yes & 9 & 2328 & 3.87 & $1.58(1.20 \text { to } 2.07)^{\star \star \star}$ & 0.92 (0.70 to 1.20$)$ \\
\hline \multicolumn{6}{|l|}{ Obesity } \\
\hline No & 92 & 36011 & 2.55 & 1.00 & 1.00 \\
\hline Yes & 2 & 986 & 2.03 & $0.79(0.46$ to 1.38$)$ & - \\
\hline \multicolumn{6}{|l|}{ Stroke } \\
\hline No & 93 & 36784 & 2.53 & 1.00 & 1.00 \\
\hline Yes & 1 & 213 & 4.69 & $1.86(0.85$ to 4.03$)$ & - \\
\hline \multicolumn{6}{|l|}{ CAD } \\
\hline No & 69 & 33530 & 2.06 & 1.00 & 1.00 \\
\hline Yes & 25 & 3468 & 7.21 & $3.50(2.93 \text { to } 4.19)^{\star \star \star}$ & $2.04(1.67 \text { to } 2.50)^{\star \star \star}$ \\
\hline \multicolumn{6}{|c|}{ Hepatitis B virus } \\
\hline No & 90 & 35843 & 2.51 & 1.00 & 1.00 \\
\hline Yes & 4 & 1154 & 3.47 & 1.38 (0.93 to 2.05$)$ & - \\
\hline \multicolumn{6}{|c|}{ Hepatitis C virus } \\
\hline No & 92 & 36509 & 2.52 & 1.00 & 1.00 \\
\hline Yes & 2 & 488 & 4.10 & 1.63 (0.94 to 2.82$)$ & - \\
\hline
\end{tabular}


Table 2 Continued

\begin{tabular}{|c|c|c|c|c|c|}
\hline Variable & Event & $\begin{array}{l}\text { Person- } \\
\text { years }\end{array}$ & Rate† & Crude HR $(95 \% \mathrm{Cl})$ & Adjusted HR $(95 \% \mathrm{Cl})$ \\
\hline \multicolumn{6}{|l|}{ IBD } \\
\hline No & 92 & 36785 & 2.50 & 1.00 & 1.00 \\
\hline Yes & 2 & 211 & 9.47 & $3.79(2.18 \text { to } 6.57)^{\star \star \star}$ & $3.21(1.87 \text { to } 5.52)^{\star \star *}$ \\
\hline \multicolumn{6}{|c|}{ Hyperthyroidism } \\
\hline No & 87 & 34335 & 2.53 & 1.00 & 1.00 \\
\hline Yes & 7 & 2662 & 2.63 & $1.94(1.60 \text { to } 2.36)^{\star \star \star}$ & 0.77 (0.56 to 1.06$)$ \\
\hline \multicolumn{6}{|c|}{ Hypothyroidism } \\
\hline No & 88 & 35359 & 2.49 & 1.00 & 1.00 \\
\hline Yes & 6 & 1638 & 3.66 & $1.47(1.06 \text { to } 2.04)^{\star}$ & 0.76 (0.54 to 1.07$)$ \\
\hline
\end{tabular}

Crude HR, relative HR.

${ }^{*} \mathrm{P}<0.05,{ }^{* *} \mathrm{p}<0.01,{ }^{* \star *} \mathrm{p}<0.001$.

†Incidence rate, per 1000 person-years.

$\ddagger$ Adjusted HR: multivariable analysis including age, sex, and comorbidities of hyperlipidaemia, diabetes, liver cirrhosis, hypertension, COPD,

CAD, IBD, hyperthyroidism and hypothyroidism.

CAD, coronary artery disease; COPD, chronic obstructive pulmonary disease; IBD, inflammatory bowel disease.

CAD (table 1). ${ }^{21}$ Hypothyroidism can lead to atherosclerosis and arterial stiffness through increased production of total and low-density lipoprotein (LDL) cholesterol, increased levels of apolipoprotein B and elevated levels of homocysteine. ${ }^{22-24}$ Furthermore, the increase in total and LDL cholesterol and apolipoprotein B is proportional to the severity of hypothyroidism. Furthermore, an autoimmune process and chronic inflammation in HT have been supposed to be directly related to the development of cardiovascular disease. ${ }^{25}$ HT and GD are generally believed to share a number of common aetiological factors, although they may have different phenotypes of the thyroid functions. It is more frequent for GD to spontaneously evolve to HT, while the development of GD from HT was quite rare. ${ }^{26-28}$ Consistent with the literature, approximately $46.6 \%$ of patients with HT with a history of hyperthyroidism ever presented the diagnosis of GD in our study.

Age, hyperlipidaemia, diabetes, liver cirrhosis, $\mathrm{CAD}$ and IBD remained the independent risk factors for cholelithiasis, as determined in multivariable analysis (table 2). The risk of cholelithiasis increased with increasing age because of increased biliary cholesterol secretion, impaired 7- $\alpha$ hydroxylase activity and bile salt synthesis, impaired gallbladder contraction, and increased exposure to lithogenic factors, although pigment stone remains the most

Table 3 Comparison of the cholelithiasis incidence densities between patients with and without Hashimoto's thyroiditis by demographic characteristics and presence or absence of a comorbidity

\begin{tabular}{|c|c|c|c|c|c|c|c|c|}
\hline \multirow[b]{3}{*}{ Variables } & \multicolumn{6}{|c|}{ Hashimoto's thyroiditis } & \multirow[b]{3}{*}{ Crude HR $(95 \% \mathrm{Cl})$} & \multirow[b]{3}{*}{$\begin{array}{l}\text { Adjusted HR } \\
(95 \% \mathrm{Cl})\end{array}$} \\
\hline & \multicolumn{3}{|l|}{ No } & \multicolumn{3}{|l|}{ Yes } & & \\
\hline & Event & $\begin{array}{l}\text { Person- } \\
\text { years }\end{array}$ & Rate† & Event & $\begin{array}{l}\text { Person- } \\
\text { years }\end{array}$ & Rate† & & \\
\hline \multicolumn{9}{|l|}{ Age, years } \\
\hline$\leq 49$ & 33 & 22137 & 1.49 & 11 & 5670 & 1.94 & $1.30(1.04 \text { to } 1.63)^{\star}$ & 1.29 (0.57 to 2.92$)$ \\
\hline $50+$ & 33 & 7371 & 4.48 & 17 & 1819 & 9.35 & $2.09(1.56 \text { to } 2.80)^{\star * *}$ & $2.59(1.33 \text { to } 5.03)^{\star \star *}$ \\
\hline \multicolumn{9}{|l|}{ Sex } \\
\hline Female & 58 & 26916 & 2.15 & 25 & 6847 & 3.65 & $1.69(1.41 \text { to } 2.03)^{\star \star \star}$ & $1.99(1.63 \text { to } 2.44)^{\star * \star}$ \\
\hline Male & 8 & 2592 & 3.09 & 3 & 642 & 4.67 & 1.51 (0.86 to 2.66$)$ & 1.33 (0.63 to 2.79$)$ \\
\hline \multicolumn{9}{|c|}{ Comorbidity } \\
\hline No & 22 & 18054 & 1.22 & 7 & 2491 & 2.81 & $2.07(1.58 \text { to } 2.71)^{\star \star \star}$ & $2.29(1.77 \text { to } 2.95)^{\star \star \star}$ \\
\hline Yes & 44 & 11454 & 3.84 & 21 & 4998 & 4.20 & 1.18 (0.92 to 1.50$)$ & $1.38(1.08 \text { to } 1.76)^{\star \star}$ \\
\hline
\end{tabular}

Crude HR, relative HR.

${ }^{*} \mathrm{P}<0.05,{ }^{* *} \mathrm{p}<0.01,{ }^{* * *} \mathrm{p}<0.001$.

†Incidence rate, per 1000 person-years.

†Adjusted HR: multivariable analysis including age, sex, and comorbidities of hyperlipidaemia, diabetes, liver cirrhosis, hypertension, chronic obstructive pulmonary disease, coronary artery disease, inflammatory bowel disease, hyperthyroidism and hypothyroidism. 
Table 4 Incidence and HR of cholelithiasis compared between non-HT cohort and patients with HT with and without thyroxine (T4) treatment

\begin{tabular}{|c|c|c|c|c|c|c|}
\hline \multirow[b]{2}{*}{ Variables } & \multirow[b]{2}{*}{$\mathbf{n}$} & \multirow[b]{2}{*}{ Event } & \multirow{2}{*}{$\begin{array}{l}\text { Person- } \\
\text { years }\end{array}$} & \multirow[b]{2}{*}{ Rate† } & \multirow{2}{*}{$\begin{array}{l}\text { Crude HR } \\
(95 \% \mathrm{Cl}) \\
\end{array}$} & \multirow[b]{2}{*}{ Adjusted HR $¥(95 \% \mathrm{Cl})$} \\
\hline & & & & & & \\
\hline Non-HT controls & 5021 & 66 & 29508 & 2.24 & 1 (reference) & 1 (reference) \\
\hline HT with T4 treatment & 712 & 16 & 4213 & 3.8 & $1.70(1.37 \text { to } 2.10)^{\star \star \star}$ & $1.94(1.51 \text { to } 2.49)^{\star \star \star}$ \\
\hline
\end{tabular}

Crude HR, relative HR.

${ }^{\star} \mathrm{P}<0.05,{ }^{* *} \mathrm{p}<0.01,{ }^{* \star *} \mathrm{p}<0.001$.

†Incidence rate, per 1000 person-years.

$\ddagger$ Adjusted HR: multivariable analysis including age, sex, and comorbidities of hyperlipidaemia, diabetes, liver cirrhosis, hypertension, chronic obstructive pulmonary disease, coronary artery disease, inflammatory bowel disease, hyperthyroidism and hypothyroidism.

HT, Hashimoto's thyroiditis.

common stone type encountered in the elderly population. ${ }^{45}$ The association between cholelithiasis and hypercholesterolaemia remains controversial; however, a low high-density lipoprotein cholesterol level and hypertriglyceridaemia are associated with an increased risk of stones. ${ }^{4}$ Diabetes, associated with insulin resistance, can lead to increased cholesterol saturation in the bile and impaired gallbladder motility. ${ }^{29}{ }^{30}$ Liver cirrhosis is associated with the development of black pigment stones because of altered pigment secretion, impaired gallbladder contraction and increased oestrogen levels. ${ }^{4}$ CAD and cholelithiasis may share a common pathophysiological mechanism of increasing cholesterol deposition in the atherosclerotic plaque and cholesterol saturation in the bile. ${ }^{3132}$ IBD can cause cholesterol stones by reducing bile acid reabsorption in the terminal ileum, and the absorbed bile acid can cause pigment stones by dissolving bilirubin and increasing its absorption in enterohepatic

Table 5 Overall incidence of cholecystectomy (per 1000 person-years) and estimated HRs according to Hashimoto's thyroiditis status by Cox proportional hazard regression model

\begin{tabular}{lll}
\hline & \multicolumn{2}{l}{ Hashimoto's thyroiditis } \\
\cline { 2 - 3 } & No & Yes \\
\cline { 2 - 3 } Incidence & $\mathbf{( n = 5 0 2 1 )}$ & $\mathbf{( n = 1 2 6 8 )}$ \\
\hline $\begin{array}{l}\text { Cholecystectomy } \\
\text { Person-years }\end{array}$ & 29678 & 7572 \\
\hline $\begin{array}{l}\text { Follow-up time (years), } \\
\text { mean } \pm \text { SD }\end{array}$ & $5.91 \pm 3.22$ & $5.98 \pm 3.23$ \\
\hline $\begin{array}{l}\text { Event, } \mathrm{n} \\
\text { Rate }\end{array}$ & 30 & 7 \\
\hline $\begin{array}{l}\text { Crude HR }(95 \% \mathrm{Cl}) \\
\text { Adjusted HR }(95 \% \mathrm{Cl}) \dagger\end{array}$ & 1 (reference) & $1.28(1.02$ to 1.61)* \\
\hline
\end{tabular}

${ }^{*} \mathrm{p}<0.05$

Crude HR, relative HR.

†Adjusted HR: multivariable analysis including age, sex, and comorbidities of hyperlipidaemia, diabetes, liver cirrhosis, hypertension, chronic obstructive pulmonary disease, coronary artery disease, inflammatory bowel disease, hyperthyroidism and hypothyroidism. cycling. ${ }^{33}$ However, a possible surveillance bias was raised because patients with comorbidities are more likely to get diagnosed with incidental cholelithiasis than patients without these morbidities. The inclusion of asymptomatic cholelithiasis in the outcome group could inadvertently tag more indications of abdominal imaging, and therefore lead to unexpected associations between some comorbidities with cholelithiasis.

Our results reveal that HT was closely related to the development of cholelithiasis, after adjustment for age, sex, hyperlipidaemia, diabetes, liver cirrhosis, hypertension, COPD, CAD, IBD, hyperthyroidism and hypothyroidism in the Cox proportional hazards regression. Furthermore, the relative risk of cholelithiasis in the HT cohort was higher than that in the non-HT cohort for patients without or with a comorbidity. In addition, the risk of cholelithiasis in the HT cohort increased with an incremental duration of follow-up after HT diagnosis (figure 2). These findings confirm an increased risk of cholelithiasis after HT diagnosis, although we could not establish the causal relationship between HT and cholelithiasis in this observational study. However, there may be a surveillance bias raised by a more incidental diagnosis on abdominal imaging due to HT as there is no routine screening of asymptomatic cholelithiasis and a vast majority of these non-HT individuals with cholelithiasis may remain undiagnosed. Furthermore, the presence of cholelithiasis may not be noted in the insurance claims data because no treatment was required. However, HT was consistently associated with the risk of cholecystectomy after we assessed the clinically relevant outcome of cholecystectomy to minimise possible misclassification of symptomatic cholelithiasis.

Consistent with the literature, our study demonstrated that HT was related to the development of cholelithiasis, and these findings might be attributed to the sequel of hypothyroidism. ${ }^{15} 34$ The possible pathophysiological mechanisms underlying the development of cholelithiasis after HT diagnosis are as follows. First, hypothyroidism reduces liver cholesterol metabolism, resulting in cholesterol supersaturation due to lack of thyroxine. ${ }^{35}$ Second, decreased bile secretion from the hepatocytes results in 
bile crystallisation. ${ }^{36}$ Third, changes in the bile composition and decreased relaxation of the sphincter of Oddi in hypothyroidism delay the flow of bile into the duodenum. Moreover, gallbladder contractility and intestinal motility are impaired in hypothyroidism. ${ }^{36-38}$ Finally, in addition to hypothyroidism, HT-associated vasculitis or oxidative stress could predispose to the development of cholelithiasis. ${ }^{39} 40$ The use of thyroxine does not seem to ameliorate the increased incidence of cholelithiasis for HT since patients with HT with $(\mathrm{aHR}=1.94,95 \%$ CI 1.51 to 2.49) and without ( $\mathrm{aHR}=1.95,95 \%$ CI 1.53 to 2.49 ) thyroxine treatment were similarly associated with a higher risk of cholelithiasis than those in the non-HT cohort and their aHRs were comparable (table 4). These findings support that the association between HT and cholelithiasis might not simply be relevant to the thyroid function.

Our study has several strengths. First, this is the first population-based cohort study on the association between HT and cholelithiasis. Additionally, we used a longitudinal database with a 12-year observation period for a large cohort size of 1000000 residents to demonstrate the association between HT and the subsequent development of cholelithiasis. Second, the Taiwan NHI programme covers healthcare for more than $99 \%$ of the residents of Taiwan under a single-payer system, and all the insurance claims for medical reimbursement have shown a substantial concordance in the literature. ${ }^{41}{ }^{42}$ Therefore, the present findings reveal an association between HT and cholelithiasis based on the real situations of Taiwan with a profoundly large sample size and can represent generalisability in Taiwan. However, more studies are required to clarify the association, which may vary with ethnicity and environment.

Our study also has several limitations. First, the evidence derived from a retrospective cohort study is generally of lower methodological quality than that from randomised trials since the retrospective cohort study is subject to many biases related to the necessary adjustments for confounding factors. Many of these factors could not be ascertained at all from the insurance claims database (eg, postmenopausal hormone use, diet, coffee, alcohol, smoking and so on), and some could only be ascertained partially (eg, obesity instead of body mass index) even though we have used the diagnosis of COPD and alcohol-related illness as replacements for the habits of smoking and alcohol consumption, respectively. Second, we could not validate the diagnosis of HT and cholelithiasis by individually reviewing the medical records. However, the NHI programme is managed by the Taiwanese government, and all insurance claims are audited based on standard diagnostic criteria for medical reimbursement. ${ }^{41} 42$ Medical providers are fined and face administrative sanction if the diagnostic coding and claims data are incorrect. Third, the 171 patients with a history of GD before evolving to HT might belong to a heterogeneous autoimmune thyroid disease group, rather than conventionally defined HT, since they often had positive antibodies and chronic inflammatory features in sonography that are difficult to differentiate from HT. However, HT was consistently associated with the risk of cholelithiasis or cholecystectomy even though we have excluded the 171 patients with a history of GD from the HT cohort. Fourth, the association between HT and cholelithiasis might be skewed by surveillance bias since patients with HT would get more opportunities for abdominal imaging studies, or the presence of cholelithiasis was not recorded in the insurance claims data because no treatment was required. However, the association has been supported by the association between cholecystectomy and HT in our study, although asymptomatic cholelithiasis and cholecystectomy might be different entities. Finally, the definite pathophysiology and the causal relationship for the association between HT and cholelithiasis could not be ascertained in this observational study and more studies are required to clarify the relationship. However, the association could not be simply explained by hypothyroidism. HT per se might be associated with the development of cholelithiasis, and was supported by our findings that the association persisted in multivariable Cox proportional hazard regression model after controlling for the confounding factors, including hyperthyroidism and hypothyroidism, Furthermore, with comparable aHRs, patients with HT with and without thyroxine treatment were similarly associated with a higher risk of cholelithiasis than those in the non-HT cohort.

In conclusion, our population-based cohort study demonstrated HT per se was associated with the development of cholelithiasis, particularly in women aged $\geq 50$ years. The risk of cholelithiasis increased with the follow-up time after a diagnosis of HT. Surveys and health education on cholelithiasis in women aged $\geq 50$ years with HT should be considered by clinicians and further prospective research should be done on this topic. The aforementioned association has been supported by the association between cholecystectomy and HT. However, inability to obtain information on several potential confounding factors and misclassification of important covariates are major limitations of the study.

\section{Author affiliations}

${ }^{1}$ Digestive Disease Center, Show Chwan Memorial Hospital, Changhua, Taiwan ${ }^{2}$ Digestive Disease Center, Changbing Show-Chwan Memorial Hospital, Changhua County, Taiwan

${ }^{3}$ Department of Food Science and Technology, Hungkuang University, Taichung, Taiwan

${ }^{4}$ Chung Chou University of Science and Technology, Changhua County, Taiwan ${ }^{5}$ Management Office for Health Data, China Medical University Hospital, Taichung, Taiwan

${ }^{6}$ College of Medicine, China Medical University, Taichung, Taiwan

${ }^{7}$ Graduate Institute of Biomedical Sciences and School of Medicine, College of Medicine, China Medical University, Taichung, Taiwan

${ }^{8}$ Department of Nuclear Medicine and PET Center, China Medical University Hospital, Taichung, Taiwan

${ }^{9}$ Department of Bioinformatics and Medical Engineering, Asia University, Taichung, Taiwan

Contributors Data collection and organisation: C-HC, C-LL, C-HK. Data analysis and interpretation: C-HC, C-LL, C-HK. Manuscript writing: C-HC, C-LL, C-HK. Final approval of the manuscript: C-HC, C-LL, C-HK. 
Funding This work was supported by grants from the Ministry of Health and Welfare, Taiwan (MOHW107-TDU-B-212-123004), China Medical University Hospital (DMR-107-192), Academia Sinica Stroke Biosignature Project (BM10701010021), MOST Clinical Trial Consortium for Stroke (MOST 106-2321-B-039-005-), TsengLien Lin Foundation, Taichung, Taiwan, and Katsuzo and Kiyo Aoshima Memorial Funds, Japan.

\section{Competing interests None declared.}

Patient consent Not required.

Ethics approval The NHIRD encrypts patient personal information to protect privacy and provides researchers with anonymous identification numbers associated with relevant claims information, including sex, date of birth, medical services received and prescriptions. Therefore, patient consent is not required to access the NHIRD. This study was approved to fulfil the condition for exemption by the Institutional Review Board (IRB) of China Medical University (CMUH-104-REC2115-CR2). The IRB also specifically waived the consent requirement.

Provenance and peer review Not commissioned; externally peer reviewed.

Data sharing statement The data set used in this study is held by the Taiwan Ministry of Health and Welfare (MOHW). The MOHW must approve our application to access these data. Any researcher interested in accessing this data set can submit an application form to the MOHW requesting access. Please contact the staff of MOHW (email: stcarolwu@mohw.gov.tw) for further assistance. Address: No 488, Sec 6, Zhongxiao E Rd, Nangang Dist, Taipei City 115, Taiwan (ROC). Tel: +886-28590-6848. All relevant data are within the paper.

Open access This is an open access article distributed in accordance with the Creative Commons Attribution Non Commercial (CC BY-NC 4.0) license, which permits others to distribute, remix, adapt, build upon this work non-commercially, and license their derivative works on different terms, provided the original work is properly cited, appropriate credit is given, any changes made indicated, and the use is non-commercial. See: http://creativecommons.org/licenses/by-nc/4.0/.

\section{REFERENCES}

1. Su CH, Lui WY, P'eng FK. Relative prevalence of gallstone diseases in Taiwan. A nationwide cooperative study. Dig Dis Sci 1992:37:764-8.

2. Kim MH, Lim BC, Myung SJ, et al. Epidemiological study on Korean gallstone disease: a nationwide cooperative study. Dig Dis Sci 1999;44:1674-83.

3. Park YH, Park SJ, Jang JY, et al. Changing patterns of gallstone disease in Korea. World J Surg 2004;28:206-10.

4. Shaffer EA. Gallstone disease: epidemiology of gallbladder stone disease. Best Pract Res Clin Gastroenterol 2006;20:981-96.

5. Chen CY, Lu CL, Huang YS, et al. Age is one of the risk factors in developing gallstone disease in Taiwan. Age Ageing 1998;27:437-41.

6. Chen $\mathrm{CH}$, Huang $\mathrm{MH}$, Yang JC, et al. Prevalence and risk factors of gallstone disease in an adult population of Taiwan: an epidemiological survey. J Gastroenterol Hepatol 2006;21:1737-43.

7. Ransohoff DF, Gracie WA, Wolfenson LB, et al. Prophylactic cholecystectomy or expectant management for silent gallstones. A decision analysis to assess survival. Ann Intern Med 1983:99:199-204.

8. Stinton LM, Myers RP, Shaffer EA. Epidemiology of gallstones. Gastroenterol Clin North Am 2010;39:157-69.

9. Rosseland AR, Glomsaker TB. Asymptomatic common bile duct stones. Eur J Gastroenterol Hepatol 2000;12:1171-3.

10. Williams EJ, Green J, Beckingham I, et al. British Society of Gastroenterology. Guidelines on the management of common bile duct stones (CBDS). Gut 2008;57:1004-21.

11. Huang $\mathrm{MH}$, Chen $\mathrm{CH}$, Yang JC, et al. Long-term outcome of percutaneous transhepatic cholangioscopic lithotomy for hepatolithiasis. Am J Gastroenterol 2003;98:2655-62.

12. Dayan CM, Daniels GH. Chronic autoimmune thyroiditis. $N$ Engl J Med 1996;335:99-107.

13. Vinay K. The Endocrine System: Robbins and Cotran Pathologic Mechanisms of Disease. 8th edn. Philidelphia, PA: Elsevier, 2010:1111-205.

14. Caturegli P, De Remigis A, Rose NR. Hashimoto thyroiditis: clinical and diagnostic criteria. Autoimmun Rev 2014;13:391-7.
15. Radetti G, Salerno M, Guzzetti C, et al. Thyroid function in children and adolescents with Hashimoto's thyroiditis after I-thyroxine discontinuation. Endocr Connect 2017;6:206-12.

16. De Luca F, Santucci S, Corica D, et al. Hashimoto's thyroiditis in childhood: presentation modes and evolution over time. Ital J Pediatr 2013;39:8.

17. Wasniewska M, Corrias $A$, Salerno $M$, et al. Outcomes of children with hashitoxicosis. Horm Res Paediatr 2012;77:36-40.

18. 2015. Database NHIR: Taiwan http://nhird.nhri.org.tw/en/index.html.

19. Chen HY, Lin CL, Kao CH. Does migraine increase the risk of glaucoma?: a population-based cohort study. Medicine 2016;95:e3670.

20. Chen $\mathrm{CH}$, Lin $\mathrm{CL}$, Kao $\mathrm{CH}$. Association between gallbladder stone disease and prostate cancer: A nationwide population-based study. Oncotarget 2016;7:64380-9.

21. Danzi S, Klein I. Thyroid disease and the cardiovascular system. Endocrinol Metab Clin North Am 2014;43:517-28.

22. Parle JV, Maisonneuve P, Sheppard MC, et al. Prediction of all-cause and cardiovascular mortality in elderly people from one low serum thyrotropin result: a 10-year cohort study. Lancet 2001;358:861-5.

23. Masaki M, Komamura K, Goda A, et al. Elevated arterial stiffness and diastolic dysfunction in subclinical hypothyroidism. Circ J 2014;78:1494-500.

24. Cappola AR, Ladenson PW. Hypothyroidism and atherosclerosis. J Clin Endocrino Metab 2003;88:2438-44.

25. Frostegård J. Autoimmunity, oxidized LDL and cardiovascular disease. Autoimmun Rev 2002;1:233-7.

26. Le Berre JP, Rousseau C, Dupuy O, et al. Unusual evolution of autoimmune hypothyroidism: occurrence of Grave's disease. Rev Med Interne 2004;25:841-3.

27. Ludgate M. Emerson $\mathrm{CH}$ : Metamorphic thyroid autoimmunity. Thyroid 2008;18:1035-7

28. Wasniewska M, Corrias A, Arrigo T, et al. Frequency of Hashimoto's thyroiditis antecedents in the history of children and adolescents with graves' disease. Horm Res Paediatr 2010;73:473-6.

29. Kahn BB, Flier JS. Obesity and insulin resistance. J Clin Invest 2000;106:473-81.

30. Abrahamsson H. Gastrointestinal motility disorders in patients with diabetes mellitus. J Intern Med 1995;237:403-9.

31. Lloyd-Jones D, Adams R, Carnethon M, et al. American Heart Association Statistics Committee and Stroke Statistics Subcommittee. Heart disease and stroke statistics-2009 update: a report from the American Heart Association Statistics Committee and Stroke Statistics Subcommittee. Circulation 2009;119:e21-e181.

32. Chavez-Tapia NC, Kinney-Novelo IM, Sifuentes-Rentería SE, et al. Association between cholecystectomy for gallstone disease and risk factors for cardiovascular disease. Ann Hepatol 2012;11:85-9.

33. Vítek L, Carey MC. Enterohepatic cycling of bilirubin as a cause of 'black' pigment gallstones in adult life. Eur J Clin Invest 2003;33:799-810.

34. Laukkarinen J, Sand J, Autio V, et al. Bile duct stone procedures are more frequent in patients with hypothyroidism. A large, registrybased, cohort study in Finland. Scand J Gastroenterol 2010;45:70-4.

35. Andreini JP, Prigge WF, Ma C, et al. Vesicles and mixed micelles in hypothyroid rat bile before and after thyroid hormone treatment: evidence for a vesicle transport system for biliary cholesterol secretion. J Lipid Res 1994;35:1405-12.

36. Field FJ, Albright E, Mathur SN. Effect of dietary cholesterol on biliary cholesterol content and bile flow in the hypothyroid rat. Gastroenterology 1986;91:297-304.

37. Inkinen J, Sand J, Arvola P, et al. Direct effect of thyroxine on pig sphincter of Oddi contractility. Dig Dis Sci 2001;46:182-6.

38. Laukkarinen J, Sand J, Aittomäki S, et al. Mechanism of the prorelaxing effect of thyroxine on the sphincter of Oddi. Scand $J$ Gastroenterol 2002;37:667-73.

39. Hernández-Rodríguez J, Tan CD, Rodríguez ER, et al. Single-organ gallbladder vasculitis: characterization and distinction from systemic vasculitis involving the gallbladder. An analysis of 61 patients. Medicine 2014;93:405-13.

40. Koppisetti S, Jenigiri B, Terron MP, et al. Reactive oxygen species and the hypomotility of the gall bladder as targets for the treatment of gallstones with melatonin: a review. Dig Dis Sci 2008;53:2592-603.

41. Wu CS, Lai MS, Gau SS, et al. Concordance between patient selfreports and claims data on clinical diagnoses, medication use, and health system utilization in Taiwan. PLoS One 2014;9:e112257.

42. Cheng CL, Lee CH, Chen PS, et al. Validation of acute myocardial infarction cases in the national health insurance research database in taiwan. J Epidemiol 2014;24:500-7. 